\title{
Substituent Effects on Solvent-Free Synthesis (MWAOS) of Dihydroquinazolinones by the Addition of Isatoic Anhydride to a Series of Phenyl-Substituted N-(Phenylmethylidene) Anilines
}

\author{
Abhilash Mullasseril \\ Veliyanad Post, Ernakulam District, Kerala 682313, India \\ Correspondence should be addressed to Abhilash Mullasseril; mabhilash@hotmail.com
}

Received 4 June 2012; Revised 3 August 2012; Accepted 3 August 2012

Academic Editor: Joaquin Campos

Copyright (C) 2013 Abhilash Mullasseril. This is an open access article distributed under the Creative Commons Attribution License, which permits unrestricted use, distribution, and reproduction in any medium, provided the original work is properly cited.

The present study concentrates on the synthesis of a series of dihydroquinazolinones by applying the green concept Microwave Assisted Organic Synthesis (MWAOS) with high atom economy. A series of phenyl-substituted N-(phenylmethylidene) anilines are coupled with isatoic anhydride using a microwave oven.

\section{Introduction}

The application of green chemistry presented a new boom of area of research in the field of organic chemistry called Microwave Assisted Organic Synthesis that particularly revolutionized the drug synthesis. Using this technique the synthesis can be achieved in a fraction of time when compared to the conventional method $[1,2]$. The first reported Diels-Alder reaction in 1931 was a perfect green one as the inventors used the most popular green solvent water $[3,4]$. The usual traditional conditions for the Diels-Aldertype reactions need refluxing for nearly $90 \mathrm{~min}$ but the aid of microwaves it has been achieved in a fraction of minutes [5]. Many microwave-assisted Diels-Alder-type reactions were also found reported with solvents like DMF, diglyme, and even in water [6,7]. But recent microwave-assisted synthesis in many cases adopts the concept of solvent-free synthesis [8]. If a solvent is needed, much care is to be given while selecting the apt solvent for Microwave Assisted Organic Synthesis (MWAOS) [9]. Most organic reactions requiring heat have been heated using traditional heat transfer equipment such as oil baths, sand baths, or heating mantles. These techniques are rather slow and create a temperature gradient within the sample. Moreover, the hot surface of the reaction vessel may result in localized overheating leading to product, substrate, and reagent decomposition when heated for prolonged periods. In contrast, when using microwave dielectric heating (the theory behind microwave heating) the energy is introduced into the chemical reactor remotely and there is no direct contact between the energy source and the reaction mixture [10]. Microwave radiation passes through the walls of the vessel heating the contents directly by taking advantage of the ability of some liquids and solids to transform electromagnetic radiation into heat. The present study concentrates on the synthesis of quinazolinones by applying the green concept Microwave Assisted Organic Synthesis (MWAOS). Many of the quinazolinones are well known as choleretic and antidiabetic agents and traditionally prepared using anthranilic acid and thionyl chloride in dry benzene [11-13]. The most possible defect of MWAOS is the explosion due to overheating but which can be effectively controlled by handling the oven professionally.

\section{Experimental Section}

The chemicals (isatoic anhydride and solvents) used for the synthesis were purchased from Merck and used as such. Azomethines were prepared according to the reported procedures and recrystallized from methanol [14]. IR spectra were recorded on a Shimadzu instrument and the absorbencies 
were reported in $\mathrm{cm}^{-1}$. The NMR spectra were recorded in Bruker $400 \mathrm{MHz}$ FT-NMR spectrometer using $\mathrm{CDCl}_{3}$ as solvent. $\mathrm{CHN}$ analysis was carried out in a Perkin Elmer CHNS analyzer. The reaction was monitored using thin layer chromatography and visualized using UV-chamber.

Microwave reactions were performed on a domestic oven of Samsung make where $10 \mathrm{sec}$ intervals of heating time controller which can be even stopped in a fraction of $1 \mathrm{sec}$ in between if needed. The equipment has a power source of $220 \mathrm{~V}, 50 \mathrm{~Hz}$, and microwave energy output $850 \mathrm{~W}$.

A series of dihydroquinazolines were prepared as per Scheme 1. An equimolar mixture of isatoic anhydride and corresponding azomethine together was powdered in a mortar and transferred in to $50 \mathrm{~mL}$ beaker of Schott Duran make. The mixture was then microwave irradiated without solvent for $120-540 \mathrm{Sec}$ at a temperature of $65-70^{\circ} \mathrm{C}$ (may not be accurate as measured outside the oven) and the molten mass was worked up as reported [15]. The work entitled reinvestigation of the reaction of iminoketene with 1-substituted 3,4dihydroisoquinolines; an unusual C-C cleavage is also found informative [16].

\section{Characterization}

The characterizations were done using instruments like IR spectrometer, CHN-analyzer, and $1 \mathrm{HNMR}$. The structures were confirmed based on obtained spectral data. The colour varies from light orange to dark red as the colour of azomethines. The products $\mathbf{4 a}, \mathbf{4 b}, \mathbf{4 c}$ and $\mathbf{4 e}$ and $\mathbf{5 d}, \mathbf{5 f}$, and $\mathbf{5 g}$ were found formed.

(4a) Spectral Data for 2,3-Diphenyl-2,3-dihydroquinazolin4(1H)-one. IR ( $\left.\mathrm{KBr}, \mathrm{cm}^{-1}\right) 3300$ ( $\mathrm{NH}$ str.), 1645 ( $\mathrm{C}=\mathrm{O}$ str.), $1512,1485,1391,1310,1256,1162,1034,872,751,703,629$, 548.

Elemental analysis calculated for $\mathrm{C}_{20} \mathrm{H}_{16} \mathrm{~N}_{2} \mathrm{O}$ : C, 79.98; H, 5.37; N, 9.33\%. Found: C, 80.04; H, 5.30; N, 9.45\%.

${ }^{1} \operatorname{HNMR}(\delta, \mathrm{ppm}): 7.99(\mathrm{~d}, 1 \mathrm{H}), 7.97(\mathrm{t}, 1 \mathrm{H}), 7.33(\mathrm{~d}, 1 \mathrm{H})$, 7.30-7.21(m, 5H), 7.14-7.01 (m, 5H), $6.86(\mathrm{t}, 1 \mathrm{H}), 6.07(\mathrm{~s}$, $1 \mathrm{H}), 4.73$ (s, broad, $1 \mathrm{H} \mathrm{D}_{2} \mathrm{O}$ exchangeable, $\mathrm{NH}$ ).

(4b) Spectral Data for 2-(2-Hydroxyphenyl)-3-phenyl-2,3Dihydroquinazolin-4(1H)-one. IR $\left(\mathrm{KBr}, \mathrm{cm}^{-1}\right) 3310$ (broad $\mathrm{NH}$ str., $\mathrm{OH}$ ), 1645 (C=O str.), 1512, 1246, 1166, 1030, 852, 756, 703, 548.

Elemental analysis calculated for $\mathrm{C}_{20} \mathrm{H}_{16} \mathrm{~N}_{2} \mathrm{O}_{2}$ : C, 75.93; H, 5.10; N, 8.86\%. Found: C, 76.20; H, 4.92; N, 8.62\%.

${ }^{1} \operatorname{HNMR}(\delta, \mathrm{ppm}): 7.99(\mathrm{~d}, 1 \mathrm{H}), 7.97(\mathrm{t}, 1 \mathrm{H}), 7.86(\mathrm{~d}, 1 \mathrm{H})$, $7.85(\mathrm{t}, 2 \mathrm{H}), 7.62(\mathrm{~d}, 1 \mathrm{H}), 7.33(\mathrm{~d}, 1 \mathrm{H}), 7.30-7.21(\mathrm{~m}, 5 \mathrm{H}), 6.86$ $(\mathrm{t}, 1 \mathrm{H}), 6.07(\mathrm{~s}, 1 \mathrm{H}), 5.30\left(\mathrm{~s}, 1 \mathrm{H}, \mathrm{D}_{2} \mathrm{O}\right.$ exchangeable) $4.73(\mathrm{~s}$, broad, $1 \mathrm{H} \mathrm{D}_{2} \mathrm{O}$ exchangeable).

(4c) Spectral Data for 2-(3-Hydroxyphenyl)-3-phenyl-2,3Dihydroquinazolin-4(1H)-one. IR $\left(\mathrm{KBr}, \mathrm{cm}^{-1}\right) 3350$ (broad NH str., OH), 1648 (C=O str.), 1510, 1246, 1172, 1035, 856, 754, 703, 548.

Elemental analysis calculated for $\mathrm{C}_{20} \mathrm{H}_{16} \mathrm{~N}_{2} \mathrm{O}_{2}$ : C, 75.93; H, 5.10; N, 8.86\%. Found: C, 76.00; H, 4.98; N, 8.92\%.
${ }^{1} \operatorname{HNMR}(\delta, \mathrm{ppm}): 7.99$ (d, 1H), $7.97(\mathrm{t}, 1 \mathrm{H}), 7.55(\mathrm{~s}, 1 \mathrm{H})$, $7.52(\mathrm{~d}, 1 \mathrm{H}), 7.50(\mathrm{~d}, 1 \mathrm{H}), 7.45(\mathrm{t}, 1 \mathrm{H}), 7.33(\mathrm{~d}, 1 \mathrm{H}), 7.30-$ $7.21(\mathrm{~m}, 5 \mathrm{H}), 6.86(\mathrm{t}, 1 \mathrm{H}), 6.07(\mathrm{~s}, 1 \mathrm{H}), 5.30\left(\mathrm{~s}, 1 \mathrm{H} \mathrm{D} \mathrm{D}_{2} \mathrm{O}\right.$ exchangeable), 4.73 ( $\mathrm{s}, 1 \mathrm{H} \mathrm{D}_{2} \mathrm{O}$ exchangeable).

(5d) Spectral Data for 3-(4-Hydroxyphenyl)-2-phenyl-1,2dihydrocinnolin-4-ol. IR ( $\left.\mathrm{KBr}, \mathrm{cm}^{-1}\right)$ 3380(sharp, OH str.), 3348 (broad NH str., OH), 1648 (C=O str.), 1512, 1246, 1166, 1030, 852, 756, 710, 550.

Elemental analysis calculated for $\mathrm{C}_{20} \mathrm{H}_{16} \mathrm{~N}_{2} \mathrm{O}_{2}$ : C, 75.93; H, 5.10; N, 8.86\%. Found: C, 76.20; H, 4.92; N, 8.62\%.

${ }^{1} \mathrm{HNMR}(\delta, \mathrm{ppm}): 12.56$ (s, broad, $1 \mathrm{H} \mathrm{D}_{2} \mathrm{O}$ exchangeable), $8.53(\mathrm{t}, 2 \mathrm{H}), 8.42(\mathrm{~d}, 2 \mathrm{H}), 7.80(\mathrm{~d}, 2 \mathrm{H}), 7.76(\mathrm{~d}, 2 \mathrm{H})$, 7.33-7.21 ( $\mathrm{m}, 5 \mathrm{H}), 7.00$ ( $\mathrm{s}$, broad, $1 \mathrm{H} \mathrm{D}_{2} \mathrm{O}$ exchangeable), $5.30\left(\mathrm{~s}, 1 \mathrm{H} \mathrm{D}_{2} \mathrm{O}\right.$ exchangeable).

(4e) Spectral Data for 2-(2-Nitrophenyl)-3-phenyl-2,3dihydroquinazolin-4(1H)-one. IR $\left(\mathrm{KBr}, \mathrm{cm}^{-1}\right) 3290(\mathrm{NH}$ str.), 1645 ( $\mathrm{C}=\mathrm{O}$ str.), 1524-1444 $\left(\mathrm{NO}_{2}\right), 1392,1310,1256$, 1162, 1038, 872, 751, 708, 548.

Elemental analysis calculated for $\mathrm{C}_{20} \mathrm{H}_{15} \mathrm{~N}_{2} \mathrm{O}_{3}$ : C, 69.56; H, 4.38; N, 12.17\%. Found : C, 70.00; H, 4.48; N, 12.02\%.

${ }^{1} \operatorname{HNMR}(\delta, \mathrm{ppm}): 8.22(\mathrm{t}, 1 \mathrm{H}), 8.21(\mathrm{~d}, 1 \mathrm{H}), 7.99(\mathrm{~d}, 1 \mathrm{H})$, $7.97(\mathrm{t}, 1 \mathrm{H}), 7.92(\mathrm{~d}, 1 \mathrm{H}), 7.57(\mathrm{t}, 1 \mathrm{H}), 7.33(\mathrm{~d}, 1 \mathrm{H}), 7.30-7.21$ $(\mathrm{m}, 5 \mathrm{H}), 6.86(\mathrm{t}, 1 \mathrm{H}), 6.07(\mathrm{~s}, 1 \mathrm{H}), 4.73\left(\mathrm{~s}\right.$, broad, $1 \mathrm{H} \mathrm{D}_{2} \mathrm{O}$ exchangeable).

(5f) Spectral Data for 3-(3-Nitrophenyl)-2-phenyl-1,2dihydrocinnolin-4-ol. IR ( $\left.\mathrm{KBr}, \mathrm{cm}^{-1}\right) 3426$ (OH str.), 3298 (NH str.), 1648 (C=O str.), 1526-1448 $\left(\mathrm{NO}_{2}\right), 1392,1308$, 1256, 1164, 1038, 872, 754, 708, 550.

Elemental analysis calculated for $\mathrm{C}_{20} \mathrm{H}_{15} \mathrm{~N}_{2} \mathrm{O}_{3}$ : C, 69.56; H, 4.38; N, 12.17\%. Found: C, 69.22; H, 4.48; N, 12.22\%.

${ }^{1} \mathrm{HNMR}(\delta, \mathrm{ppm}): 12.26$ (s, $1 \mathrm{H} \mathrm{D}_{2} \mathrm{O}$ exchangeable), 8.69 $(\mathrm{t}, 2 \mathrm{H}), 8.50(\mathrm{~d}, 2 \mathrm{H}), 7.81(\mathrm{~s}, 1 \mathrm{H}), 7.45(\mathrm{~d}, 2 \mathrm{H}), 7.42(\mathrm{t}, 1 \mathrm{H})$, 7.32-7.22 (m, 5H), $5.2\left(1 \mathrm{H}, \mathrm{D}_{2} \mathrm{O}\right.$ exchangeable).

(5g) Spectral Data for 3-(3-Hydroxy-4-methoxyphenyl)-2phenyl-1,2-dihydrocinnolin-4-ol. IR $\left(\mathrm{KBr}, \mathrm{cm}^{-1}\right) 3456(\mathrm{OH})$, 3295 (NH str.), 1645 (C=O str.), 1512, 1392, 1308, 1256, 1038, $872,754,708,550$.

Elemental analysis calculated for $\mathrm{C}_{21} \mathrm{H}_{18} \mathrm{~N}_{2} \mathrm{O}_{3}$ : C, 72.82; $\mathrm{H}, 5.24 ; \mathrm{N}, 13.86 \%$. Found : $\mathrm{C}, 71.78 ; \mathrm{H}, 5.42 ; \mathrm{N}, 13.92 \%$.

${ }^{1} \mathrm{HNMR}(\delta, \mathrm{ppm}): 12.42\left(\mathrm{~s}, 1 \mathrm{H} \mathrm{D}_{2} \mathrm{O}\right.$ exchangeable $), 8.70$ $(\mathrm{t}, 2 \mathrm{H}), 8.68(\mathrm{~d}, 2 \mathrm{H}), 7.81(\mathrm{~s}, 1 \mathrm{H}), 7.78(\mathrm{~d}, 1 \mathrm{H}), 7.73(\mathrm{~d}, 1 \mathrm{H})$, 7.35-7.24 (m, 5H), 6.80 (s, $1 \mathrm{H} \mathrm{D}_{2} \mathrm{O}$ exchangeable), $5.1(\mathrm{~s}, 1 \mathrm{H}$ $\mathrm{D}_{2} \mathrm{O}$ exchangeable), $3.42(\mathrm{~d}, 3 \mathrm{H})$.

\section{Results and Discussion}

This study supports the formation of substituted quinazolinone products by the in situ Diels-Alder addition of isatoic anhydride with azomethines applying the concept of MWAOS. The method adopted gave a better yield (75-90\%) in a lesser time interval (less than $180 \mathrm{Sec}$ ) than the traditional method. The possible mechanism may be the following one represented in Scheme 1 in which the isatoic anhydride 1 forms an unisolable hetero diene 2 when exposed to 


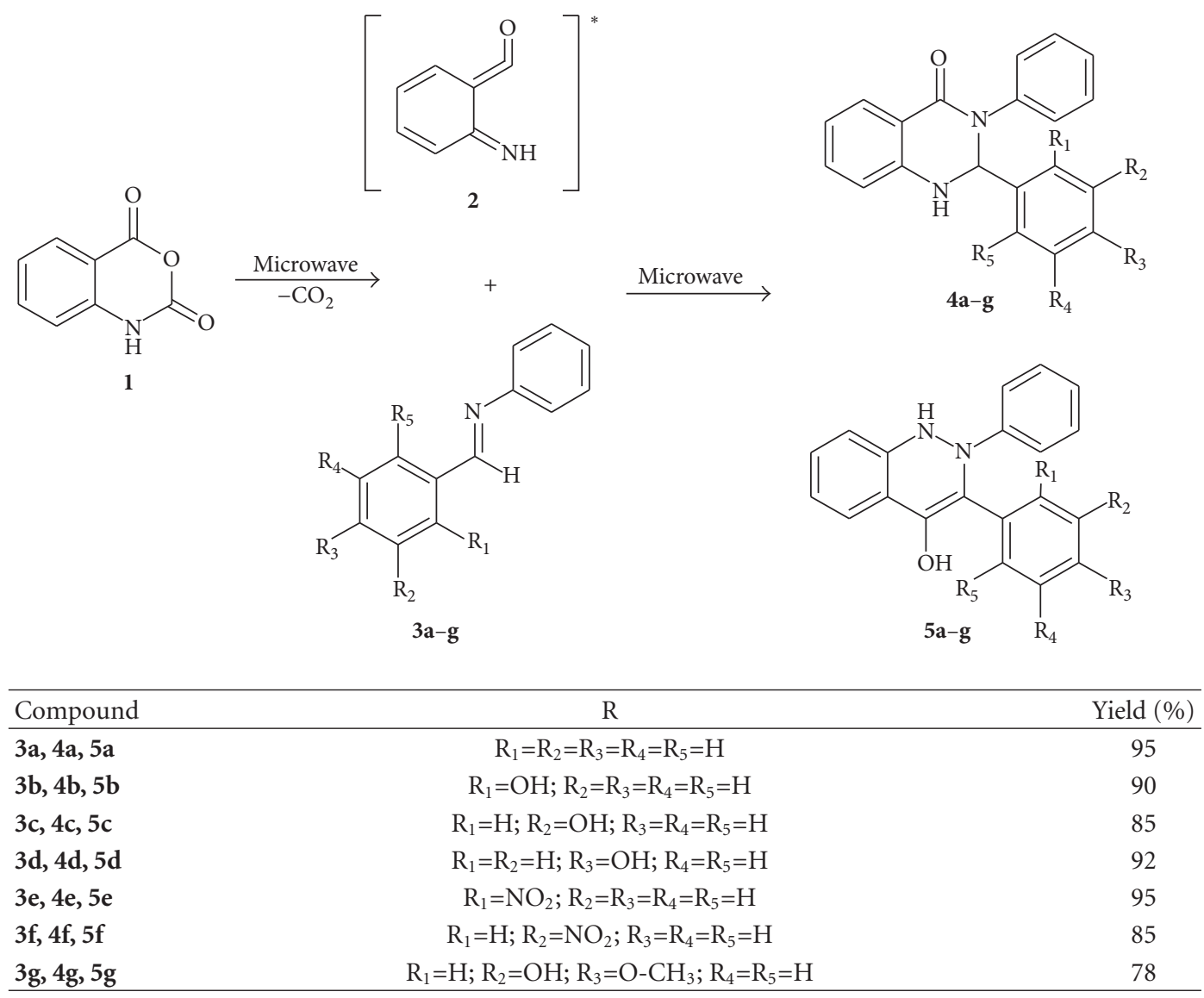

SCHEME 1

microwave and azomethine $\mathbf{3 a - g}$ as dienophile. The present study reveals that substituents on the either parts of the azomethines have considerable effect on the product formation. The NMR data of the proton of $\mathrm{CH}$ was expected as a doublet but found to be a singlet and $\mathrm{NH}$ is found as a broad singlet. The proton from $\mathrm{CH}$ was not found to be shifted to the $\mathrm{C}=\mathrm{O}$ to make its enol form $\mathrm{C}-\mathrm{OH}$. This was supported by the $\mathrm{D}_{2} \mathrm{O}$ exchange data in $\mathbf{4 a}, \mathbf{4 b}, \mathbf{4} \mathbf{c}$, and $4 \mathbf{e}$. Enolic proton peaks were clearly observed in compounds $\mathbf{5 d}, \mathbf{5 f}$, and $\mathbf{5 g}$ which were found $\mathrm{D}_{2} \mathrm{O}$ exchangeable. The time taken for the reaction to occur in microwave conditions varies as the difference in visual colour change of the reaction medium. This clearly supports the effect of substituents at the aldehydic part of the azomethines.

\section{Conclusion}

The Microwave Assisted Organic Synthesis of a series of dihydroquinazolines was achieved in short time duration with good yield and better atom economy. The process was successfully achieved with the substituted $\mathrm{N}$ (phenylmethylidene) anilines at the phenyl group. The present study clearly reveals the importance of substituents on the either parts of the azomethines on the product formation.

\section{References}

[1] F. Mavandadi and A. Pilotti, "The impact of microwave-assisted organic synthesis in drug discovery," Drug Discovery Today, vol. 11, no. 3-4, pp. 165-174, 2006.

[2] C. O. Kappe and D. Dallinger, "The impact of microwave synthesis on drug discovery," Nature Reviews Drug Discovery, vol. 5, no. 1, pp. 51-63, 2006.

[3] O. Diels and K. Alder, "Synthesen in der hydroaromatischen Reihe. XII. Mitteilung. ("Dien-Synthesen" sauerstoffhaltiger Heteroringe. 2. Dien-Synthesen des Furans.)," Liebigs Annalen der Chemie, vol. 490, no. 1, pp. 243-257, 1931.

[4] R. Woodward and H. Baer, "The reaction of furan with maleic anhydride," Journal of the American Chemical Society, vol. 70, no. 3, pp. 1161-1166, 1948.

[5] O. C. Dermer and J. King, "Purification of anthracene," Journal of the American Chemical Society, vol. 63, no. 11, article 3232, 1941.

[6] S. S. Bari, A. K. Bose, A. G. Chaudhary, M. S. Manhas, V. S. Raju, and E. W. Robb, "Reactions accelerated by microwave radiation in the undergraduate organic laboratory," Journal of Chemical Education, vol. 69, no. 11, pp. 938-939, 1992.

[7] R. J. Giguere, T. L. Bray, and S. M. Duncan, "Application of commercial microwave ovens to organic synthesis," Tetrahedron Letters, vol. 27, no. 41, pp. 4945-4948, 1986.

[8] C. O. Kappe and A. Stadler, Microwaves in Organic Synthesis, Wiley-VCH, Weinheim, Germany, 2005. 
[9] D. Michael, P. Mingos, and D. R. Baghrust, "Tilden lecture. Applications of microwave dielectric heating effects to synthetic problems in chemistry," Chemical Society Reviews, vol. 20, no. 1, pp. 1-47, 1991.

[10] C. Gabriel, S. Gabriel, E. H. Grant, B. S. J. Halstead, and D. M. P. Mingos, "Dielectric parameters relevant to microwave dielectric heating," Chemical Society Reviews, vol. 27, no. 3, pp. 213-223, 1998.

[11] M. Koizumi, Japan Kokai 77,09, 978 Chem.Abst. 53366b, 1977.

[12] J. Garin, P. Merino, J. Orduna, T. Tejero, and S. Uriel, “On the reaction of anthranilic acid with thionyl chloride: the actual structure of 'Kametani's sulfinamide anhydride,"' Tetrahedron Letters, vol. 32, no. 27, pp. 3263-3264, 1991.

[13] T. Kametani, C. van Loc, T. Higa, M. Koizumi, M. Ihara, and K. Fukumoto, "Iminoketene cycloaddition. 2. Total syntheses of arborine, glycosminine, and rutecarpine by condensation of iminoketene with amides," Journal of the American Chemical Society, vol. 99, no. 7, pp. 2306-2309, 1977.

[14] B. S. Furniss, A. J. Hannaford, V. Rogers, P. W. G. Smith, and A. R. Tatchell, Vogel's Text Book of Practical Organic Chemistry, London ELBS, 4th edition, 1980.

[15] E. J. Domenic, M. Lopez, and T. Baby, "Microwave-assisted addition of azomethines to isatoic anhydride," Journal of Chemical Sciences, vol. 119, no. 1, pp. 47-51, 2007.

[16] V. K. Kansal and A. P. Bhaduri, "Reinvestigation of the reaction of iminoketene with 1-substituted 3,4dihydroisoquinolines-an unusual C-C cleavage," Journal Für Praktische Chemie, vol. 323, no. 6, pp. 989-991, 1981. 

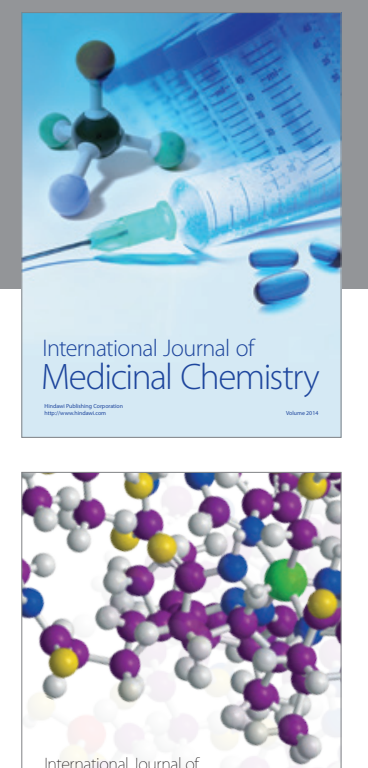

\section{Carbohydrate} Chemistry

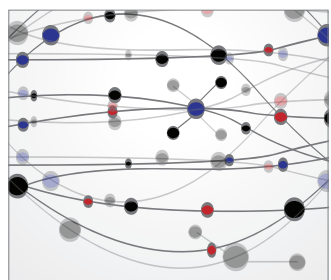

The Scientific World Journal
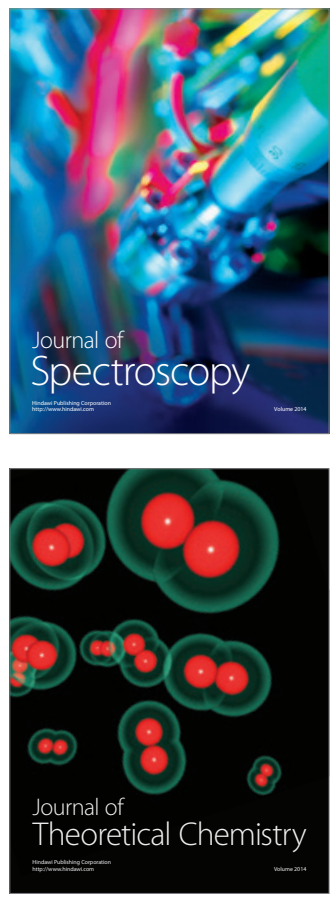
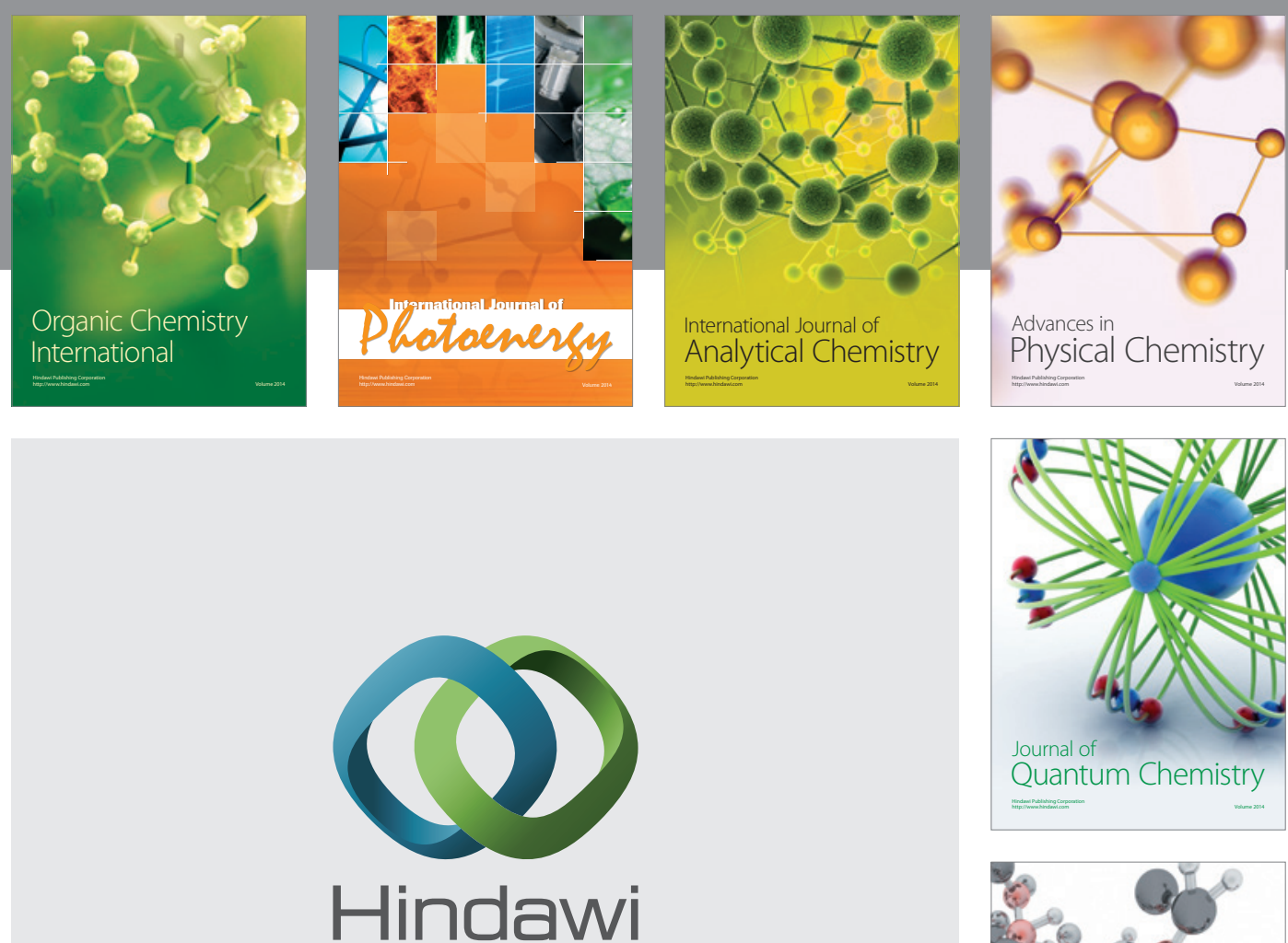

Submit your manuscripts at

http://www.hindawi.com

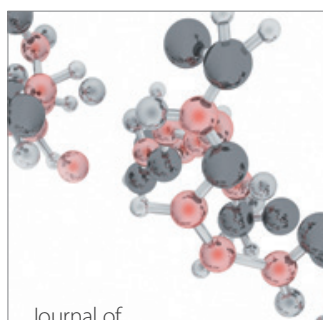

Analytical Methods

in Chemistry

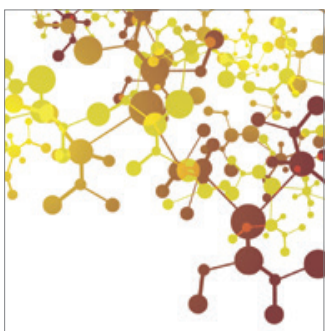

Journal of

Applied Chemistry

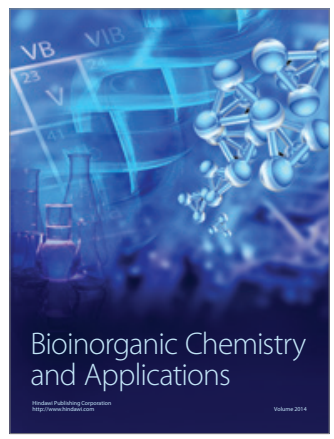

Inorganic Chemistry
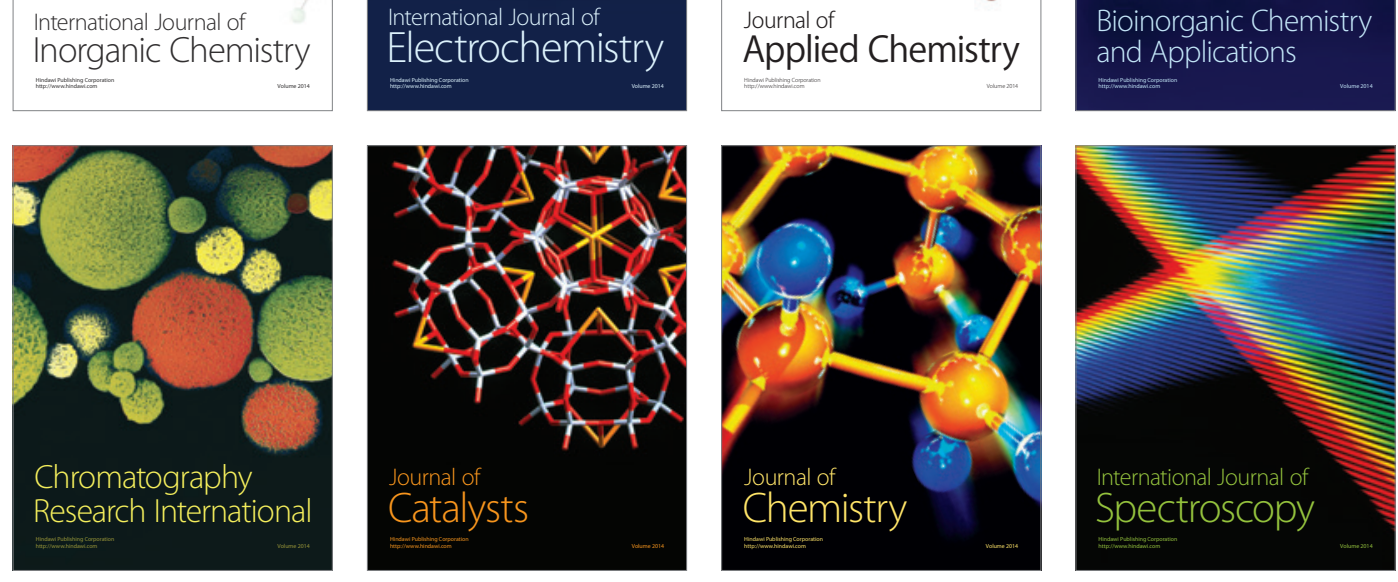